indorsed by Dr. C. M. Hobby at that time in the discussion which followed; and is again set forth by him in his letter in connection with your remarks under the above caption.

A serious obstacle in the way of reform or greater conservatism may be found, however, in the ideas which patients before seeking medical advice, have obtained upon the subject through reading (or hearing) about the wonderful cures of obstinate headaches and other maladies by the wearing of properly selected spectacles. They almost demand spectacles.

It is hardly possible to prevent, or even exercise censorship upon, the appearance of medical articles in the public prints; but if medical journals would sift exaggerations more carefully from the articles of enthusiasts in the profession, it might be spared some reproach. Truly yours,

H. B. Young.

\section{Fluid Drinks in Laparotomy Cases.}

Youngstown, OHio, Feb. 13, 1894.

To the Editor:-I have just finished reading the excellent article entitled, "Fluid Drinks after Laparotomy," by F. Byron Robinson, in current issue of the Jovrval.

Although I agree with him, that fluids are called for by the system with a special intensity after laparotomy; and that the patient is in the same condition as Tantalus, with even a greater burden to bear-that of a surgical condition is superadded; yet I think we can supply the fluid to the system in a better manner than by giving it by the mouth and stomach.

For some time $I$ have been conducting experiments upon myself, regarding the absorption and elimination of water from the bowel.

We all know that a large enema, by distending the bowel will bring on increased peristalsis, and thus cause it to be expelled within a few moments. I have found by experimenting upon my patients and myself that if a small quantity, say eight ounces, be thrown into the bowel, it will not be expelled, but will be absorbed and eliminated through the kidneys. Not only this, but it seems to so stimulate the kidneys that not only the quantity thrown into the bowel, but a much increased amount is eliminated.

To-day at 12 r. I used in this manner eight ounces of water, and rested in a reclining position half an hour. At 2, 3:30 and 5 P.M... I urinated freely, the total amount being thirty ounces. This without any variation in my ordinary food supply, and no diuretics. Yesterday, kidneys acted in the usual manner, and I expect the same conditions to morrow unless I repeat the experiment. I have tortured my patients just as Dr. Robinson says 'Tait does. I also have given fluids by the mouth, but more often with bad than good results.

Since using the above method, I have never heard the cry: "Water, water! For God's sake give me water!" so of ten heard by all operators who give no fluids. I usually have the nurse give an enema of eight ounces of water as soon as patient asks for a drink, and that ends the trouble for some time. In the course of an hour or so, the kidneys act freely, also the skin, thus eliminating from the system the effects of the anesthetic, and the effete matters of the blood. By this method a large quantity of water may be restored to the circulation at once, thus replacing the amount removed by depleting salines.

Although it is a supposed physiologic fact, that the seat of thirst is in the throat, fet I know by experience and expressions of gratitude from patients that the semsation of thirst is fully and freely gratified. I do not know that I ever saw this subject brought out in journals or text-books, and although I may have seen the idea at some time elsewhere, I think it worthy of consideration.

$$
\text { Very respectfully, }
$$

$$
\text { J. A. Dickson. }
$$

\section{The IIyposulphites in Infectious Diseases.}

$$
\text { New Orleans, La., Feb. 12, } 1894 .
$$

To the Editor:-My article upon the value of the sulphites and hy posulphites in the treatment of zymotic diseases, pub- lished in the Jounval of February 3 , has already elicited testimony of their value in the treatment of yellow fever, scarlet fever and diphtheria, as will be shown by the letters of Dr. T. O. Summers of Waukesha, Wis., and Dr. Elisha Chenery of Boston, Mass.

I shall take pleasure in sending you for our valuable JovrNsl, dear Doctor, from time to time, any additional testimony which I may receive upon this important subject. With great respect and high esteem, I remain, truly your friend. Joseph Jones, M.D., LL.D.

Professor of Chemistry and Nedical Jurisprudence, Tulane University of Jouisiana.

Dr. Joseph Jones, New Orleans, La.

Dear Sir:-I confess to no little chagrin, as well as sur. prise, at your statement in a paper on the value of the hyposulphites, that you had "no facts with which to prove" the efficacy of their use in yellow fever, and your regret that your suggestion of their use was not put to the test in the late epidemic at Brunswick. No doubt you have forgotten that in 1879 , after the terrible epidemic in Memphis, I called upon you and laid before you for inspection my little work on yellow fever just then issued in which, in the chapters on prophylaxis and treatment, the use of the hyposulphites was strenuously advocated and supported by the report of hundreds of cases. This was also confirmed by my work in 1888 in Jacksonville, and extensively reported at that time. When I wrote the work on yellow fever I was Profeisor of Anatomy in the Vanderbilt University of Nashville, where you once held the chair of Physiology, and for this reason I thought it strange that you should have so completely ignored my work. Respectfully,

T. O. Summers, M.D.

Boston, Feb. 5, 1894.

Joseph Jones, M.D., L.L.D. :

Dear Sir:-I have just received the Journal of the American Medical Association of February 3, containing your article on the sulphites and hyposulphites of sodium in relation to some of the zymotic diseases. I was to lecture to-day on diphtheria and had only a moment to run over your points, and so was not so prepared to use your statements as I should have gladly done.

I saw Professor Polli's statement as early as 1862 or '3, I think, and began the use of the hyposulphite of sodium as early as 1863 in diphtheria. I had an urgent case in an only daughter who was scrofulous, her tonsils quite meeting together. I was at my wits' end for a remedy and resolved to try the bisulphite and sent for it but could not obtain it. The apothecary, however, sent me the hyposulphite, saying that he thought I could use it. I did so and saved my frantically delirious little girl.

Now if you can get at the files of the Boston Medical and Surgical Journal for June 8, 1876, you will find an article I wrote which I think will interest you. It is on page 657 and is entitled: "Diphtheria Successfully Treated."

There are some cases it does not appear to act so well in, and I suspect it may be owing to too old hy posulphite which has changed to the sulphate, or to the lack of stomach action on it to eliminate its sulphurous acid. I wish you could make some experiments to determine these points.

While isolation is a sure preventive, I regard the use of the hyposulphite invaluable in cases which can not be isolated.

I have used the medicine also in scarlet fever with remarkable success. In one family of two children one came down with scarlet fever and the other took the hyposulphite and escaped the disease. I have used it in the early stage of typhoid fever and thought it very useful in mitigating the disease. In some cases of small children I have relied 
almost wholly on the salt and do not swab their throats. I think the medicine should be given pretty strong and frequently, moderating treatment in both respects if the bowels are much affected. During the course of the case or afterwards, iron and the bitter tonics should be given.

Now it has never occurred to me to have a case where I began early, where the patch afterward traveled into the larynx. It seems to me that the vigorous early treatment with the hyposulphite is as near a specific for both diphtheria and scarlet fever as we have yet found. I hope you will be able to produce more evidence in its favor, and you are at liberty to use this communication any way you see fit.

I hope the profession will soon be able to discriminate between diphtheria and its sequelæ, the septicemia. They run so closely into each other most physicians are still regarding the latter as a real part of the former. I do not so consider them and believe if we properiy treat and timely treat diphtheria we shall save from the latter and so save the patients. I think few cases treated energetically at first with the hyposulphite will ever be followed by paralysis. The hyposulphite has done so well for me I have not been disposed to try the other forms. Since that article my experience has confirmed my former confidence in the medicine. I think I was the first one to use it in these cases.

$$
\text { Very truly, }
$$

E. Chenery.

\section{Care of the Vaccinated.}

Mt. Pleasant, Iowa, Feb. 16, 1894.

To the Editor:-Smallpox being now so prevalent and vaccination the order of the day, may it not be well to consider at this time a seemingly little matter in connection with the latter subject? Those vaccinated go about and mingle freely with others in the usual way. The latter do not know the former are vaccinated, and subject them to roughness which they would not do if they knew they had a vaccine spot on their arm or body. They seize them, grasp or stroke them at this very spot, ignorant of the damage they are doing, and having no means of knowing it until the person cries out, and then the pain and damage has been done-most frequently, perhaps, among school children and other young persons.

Something to distinguish and forewarn, and protect the vaccinated person from this pain and unpleasantness, and the spot from damage, should be adopted; something to be universally understood as indicating the person, and spot of vaccination. For instance, a band of colored cloth or a square piece of the same sewed on the sleeve of the coat or dress, or other index to be adopted by common consent. This would keep off many strokes and pinches which, besides the discomfort to the patient, disturb the inflammatory processes and proper formation of the pustules, and invite other results such as ulceration and sloughing where otherwise a possible good result might have been reached.

Thus might also be avoided the occurrence of doubt as to the value of the vaccination, and expense and other adverse contingencies of a renewal of the vaccination. Very truly,

H. L. Green.

\section{Johns Hopkins Hospital Reports.}

Kasota, Minn., Feb. 17, 1894.

To the Editor:-I see in Book Notices of Journat of February 17 , the notice of the Johns Hopkins Hospital Reports, but it does not state the name of the publishers.

If published by the Journal send it to me with bill, or kindly inform me where it is published.

$$
\text { Yours respectfully, }
$$

W. R. HAND.

The book is published by the Johns Hopkins University. Please address them direct.-[EDitor.]

\section{ASSOCIATION NEWS}

The Association Train will leave Chicago Monday, May 28, via Santa Fe R. R., Denver \& Western, and Southern Pacific, for San Francisco via Denver, Colorado Springs, Leadville,
Manitou, Glenwood Springs, Salt Lake, Ogden, Truckee and Sacramento. Returning, after the meeting, the train will pass through Sacramento and Northern California to Portland, thence east by way of the Northern Pacific R. R. to St. Paul. A stop over at Yellowstone National Park for those who desire it has been arranged, and it is understood that at several places on the journey there will be short stops. President Hibberd's party in a special car join the train at Chicago, and the St. Louis party are expected to join at Kansas City. From all points east and south, concentration on this train should be effected at Chicago and St. Louis.

Section of Neurology and Medical Jurisprudence, American Medical Association.-The AMERICAN MEDICAL Assocration will meet at San Francisco, Cal., during the first week in June, 1894, and as it is desired to make the meeting of the Section on Neurology and Medical Jurisprudence of the Association one of unusual interest and value, you are earnestly requested to contribute to this end by the presentation of a written communication on some neurologic or medico-legal subject, or by bringing for exhibition and discussion anatomic or pathologic specimens.

If you have not yet chosen a subject, but are willing to take part in the work of the Section, please notify the Secretary at once of this initention, and as soon as possible forward the title of your contribution. It will facilitate the work of the Section to send an outline of your paper. A preliminary program will be published during March.

Frank P. Norbury, Secretary.

Jacksonville, Il]. Officers of the Section.-James G. Kiernan, M.D., Chairman,
910 , 103 State Street, Chicago, Ill.; Frank P. Norbury, M.D., Secretary, Jacksonville, Ill.

Executive Committee.-O. Everts, M.D., Cincinnati, Ohio; H. N. Moyer, M.D., Chicago, Ill.; C. K. Mills, M.D., Philadelphia, Pa.

\section{SOCIETY NEWS.}

Bucks County, Pa., Medical Society.-The Bucks County Medical Society held its midwinter meeting in Quakertown on January 31. Dr. Estes, Surgeon-in-Chief of St. Luke's Hospital, Bethlehem, addressed the meeting.

The Tri-State Medical Society of Iowa, Illinois and Missouri, will meet at Kansas City, April 3 and 4. All reputable members of the medical profession in the three States are eligible to membership, and are cordially invited to be present and participate in the deliberations.

Grand Rapids Academy of Medicine.-At the annual meeting of the Grand Rapids Academy of Medicine of Michigan, held in Grand Rapids Feb 5, 1894, the following named officers were chosen to serve the ensuing year: President, Austin J. Pressey, M.D.; Vice-President, Frances A. Rutherford, M.D.; Secretary, Louis A. Roller, M.D.; Treasurer, Samuel R. Wooster, M.D.

The Fiftieth Anniversary of the Lancaster County, ( $\mathrm{Pa}$.), Medical Society.-The proceedings of the fiftieth annual meeting of the Medical Society of the city and county of Lancaster. This was an occasion of more than ordinary interest, owing to various causes, one of them being the fact that it is the oldest in the United States, with the exception of four in cities on the Atlantic sea-board. Another interesting fact is that John L. Atlee and D. Hayes Agnew, names which have shed as much luster on American medicine as any that have adorned the profession, were among its founders. The only one of the founders present at this meeting was the venerable J. Augustus Ehler.

The writer knew nearly all of the original members and for many of them entertained the highest veneration and respect. The present membership worthily sustains the reputation of its founders, the Society being one of the most active in the State of Pennsylvania and taking a deep inter- 